\title{
Thickness suitability of prebiotic dairy desserts: Relationship with rheological properties
}

\author{
P.L. Arcia ${ }^{\mathrm{a}, \mathrm{b}}$, E. Costell ${ }^{\mathrm{a}}$, A. Tárrega ${ }^{\mathrm{a}, *}$ \\ a Physical and Sensory Properties Laboratory, Instituto de Agroquímica y Tecnología de Alimentos, CSIC. P.O. Box 73, 46100 Burjassot (Valencia), Spain \\ b Laboratorio Tecnológico del Uruguay, Av. Italia 6201, C.P. 11500, Montevideo, Uruguay
}

\section{A R T I C L E I N F O}

Article history:

Received 18 May 2010

Accepted 16 September 2010

Available online $\mathrm{xxxx}$

\section{Keywords:}

Inulin

Rheology

Adequacy of thickness

JAR

\begin{abstract}
A B S T R A C T
In food product development it is important to know to what extent changes in formulation modifies the product, affecting its sensory properties and acceptability. Addition of polysaccharides like inulin can affect product structure in particular, modifying both rheological behaviour and perceived texture. The aim of this work was to assess to what extent rheological properties can explain the acceptability of thickness perceived by consumers in starch-based desserts. Low-fat dairy desserts were prepared varying the concentration of sucrose, flavor aroma and the fat replacer with prebiotic properties (inulin) but with fixed amounts of skimmed milk and starch. The rheological behavior was characterized and the level of sample thickness suitability was evaluated by a total of 100 consumers using a 5 -point JAR scale ( $1=$ too weak, $3=$ just about right; $5=$ too strong). Results indicated that flow and viscoelastic parameters varied among samples depending on inulin and sucrose concentration. According to sensory results, thickness suitability varied greatly between samples. The relationships between instrumental and sensory results are studied and discussed.
\end{abstract}

(C) 2010 Elsevier Ltd. All rights reserved.

\section{Introduction}

Functional product development provides an opportunity to contribute to the improvement of food quality and consumer health and well-being (Hasler, 1998; Milner, 1999). A common approach employed in the food industry to develop these kinds of added-value foods involves the addition of a healthy component. It is important to know to what extent this new component modifies the product, affecting its sensory properties. In the case of macromolecules such as polysaccharides or proteins, changes in composition can affect product structure in particular, modifying both rheological behaviour and perceived texture (Dickinson, 2007; Purwanti, van der Goot, Boom, \& Vereijken, 2010).

For liquid and semisolid products, thickness is the textural attribute that most influences consumer response, though smoothness and creaminess are also influential (de Wijk, van Gemert, Terpstra, \& Wilkinson, 2003; González-Tomás \& Costell, 2006). In semisolid products with complex rheological behaviour (thixotropy, pseudoplasticity and viscoelasticity), studies aimed at identifying the physical stimuli responsible for thickness perception have proposed different indexes (Van Vliet, 2002). The initial resistance to flow (yield stress value), storage modulus at $1 \mathrm{~Hz}$ (Tárrega \& Costell, 2007) and the complex viscosity at $50 \mathrm{rad} \mathrm{s}^{-1}$ (Hill, Mitchell, \& Sherman, 1995; Richardson, Morris, Ross-Murphy, Taylor, \& Dea, 1989) have shown

\footnotetext{
* Corresponding author. Tel.: + 3496 3900022; fax: + 34963636301 E-mail address: atarrega@iata.csic.es (A. Tárrega).
}

significant correlations with thickness intensity. However one must recognize that acceptability may not always be directly related with sensory attribute intensity but rather with its adequacy (Costell, Tárrega, \& Bayarri, 2010). Traditionally, perceptible differences in food attributes are evaluated using sensory descriptive analysis by trained judges while hedonic aspects are evaluated separately by consumers. JAR scale is an alternative method that combines both intensity attribute and hedonics assessed by consumers (Gacula, Rutenbeck, Pollack, Resurreccion, \& Moskowitz, 2007). This technique provides information on how consumers feel about the product attribute and then determines both the adequate attribute level for this product and how much a sample deviates from this ideal point.

Inulin is a very interesting functional ingredient that is increasingly being used to formulate new fibre-enriched products or with prebiotic benefits (Roberfroid, 2007). Chemically it is a polymer of fructose units that can have different chain lengths. Long-chain inulin can modify texture because it crystallises in presence of water forming a particle network structure (Chiavaro, Vittadini, \& Corradini, 2007; Hébette et al., 1998). Consequently it is being used in low-fat products to improve creaminess and consistency, mimicking those of full-fat products (González-Tomás, Bayarri, Coll-Marqués \& Costell, 2009; Paseephol, Small \& Sherkat, 2008; Soukoulis, Lebesi, \& Tzia, 2009; Tárrega \& Costell, 2006). Nutritional studies have recommended the combination of inulin with different chain lengths in order to maximise its fermentative and prebiotic effects (Biedrzycka \& Bielecka, 2004; Coudray, Tressol, Gueux, \& Rayssiguier, 2003). From a technological viewpoint the use of mixedchain inulin, instead of only long-chain inulin, may decrease its thickening ability. Tárrega, Rocafull, and Costell (2010) showed that 
7.5\% of a mixture of short and long-chain inulin 50:50 was still able to modify the rheological properties of a low-fat dairy dessert. However this effect can also depend on inulin concentration (Bayarri, Chuliá \& Costell, 2010) and on its possible interaction with other ingredients and their concentrations. Sucrose is a common ingredient used as sweetener in dairy dessert. In starch-based systems whose characteristics depend on interactions between starch and water, the presence of sucrose that reduces both water activity and translational mobility of water can affect gelatinization temperature, starch granules swelling or viscosity (Kohyama, \& Nishinari, 1991; Kruger, Ferrero \& Zaritzky, 2003). It is expected that structure and rheological behaviour of starch-inulinsucrose systems will be determined by water competition among this three components.

Some studies in the literature indicate that addition of aroma compounds can modify rheological behaviour of food products (Cayot, Lafarge, Arvisenet, \& Taisant, 2000; Lubbers \& Decourcelle, 2004). In starch-based desserts (Cayot et al., 2000) addition of different aroma compounds (limonene, ethyl vanillin or isoamyl acetate) resulted in slightly weaker gels that was attributed to the interaction among aroma compound and amylopectin fraction. Other authors have also observed that perceived texture can be affected by aroma compounds through perceptual cross-modal interaction flavour-texture (Bult, De Wijk, \& Hummel, 2007).

The present work aims to study the effect of composition on the rheological behaviour and thickness adequacy in a prebiotic dairy dessert and to establish whether the desirable level of thickness can be explained by rheological-parameter variation.

\section{Material and methods}

\subsection{Sample composition and preparation}

Samples were prepared using the following ingredients: skimmed milk powder (Central Lechera Asturiana, Spain), modified tapioca starch with a medium crosslinking degree $\left(C^{*}\right.$ CreamTex 75,720. Cerestar, Spain), two types of inulin: long-chain (Frutafit ${ }^{\circledR}$ TEX) and short-chain (Frutafit ${ }^{\circledR}$ CLR) (Sensus, Brenntag Química, Spain), commercial sucrose, lemon flavor 16508A (Lucta SA, Spain), colorant T-PT8 - WAS, solution of curcumin from turmeric root in polysorbate (CHR Hansen SA, Spain), mineral water (Font Vella, Spain) and preservatives: potassium sorbate and potassium benzoate (Panreac, Quimica SA, Spain).

In the formulation of samples, contents of starch (3.75\%), milk (75\%), colorant $(37.5 \mathrm{ppm})$ and preservatives (potassium sorbate $500 \mathrm{ppm}$; potassium benzoate $500 \mathrm{ppm}$ ) were constant, while inulin, sucrose and lemon flavor were defined according to a three-factor central composite design with replicates of the central point. It comprised nineteen points: eight factorial, six axial and five central points (Table 1).

\section{Table 1}

Experimental design and composition for samples of low-fat dairy dessert.

\begin{tabular}{lccl}
\hline Sample & Sucrose \% & Lemon flavor ppm & Inulin \% \\
\hline 1 & 7 & 75 & 4.5 \\
2 & 13 & 75 & 4.5 \\
3 & 7 & 175 & 4.5 \\
4 & 13 & 175 & 4.5 \\
5 & 7 & 75 & 7.5 \\
6 & 13 & 75 & 7.5 \\
7 & 7 & 175 & 7.5 \\
8 & 13 & 175 & 7.5 \\
9 & 10 & 125 & 6 \\
10 & 4 & 125 & 6 \\
11 & 16 & 125 & 6 \\
12 & 10 & 25 & 6 \\
13 & 10 & 225 & 6 \\
14 & 10 & 125 & 3 \\
15 & 10 & 125 & 9 \\
$16-19^{\text {a }}$ & 10 & 125 & 6 \\
\hline
\end{tabular}

\footnotetext{
a Samples 16 to 19 are replication of the central point (sample 9).
}

Skimmed milk ( $0.11 \mathrm{~g}$ fat/100 $\mathrm{g}$ ) was prepared $24 \mathrm{~h}$ in advance by dissolving milk powder (14.4\%) in mineral water and storing under refrigeration $\left(4 \pm 1{ }^{\circ} \mathrm{C}\right)$. Inulin used corresponded to a mixture of long-chain and short-chain inulin in a ratio of 50:50.

Samples were prepared in batches of $800 \mathrm{~g}$. Starch, sucrose, inulin, and colorant at $20^{\circ} \mathrm{C}$ and milk at $6{ }^{\circ} \mathrm{C}$ were weighed in a flask and mixed under magnetic stirring (paddle stirrer, Heidolph RZR 1, Germany) for 10 min at approximately $20^{\circ} \mathrm{C}$. The flask was placed in a water bath at $97 \pm 1{ }^{\circ} \mathrm{C}$ and stirred constantly with a propeller stirrer for $25 \mathrm{~min}$. Then the sample was cooled in a water bath at $20^{\circ} \mathrm{C}$ with stirring for $10 \mathrm{~min}$. A small portion of long-chain inulin ( $0.2 \%$ of total weight of sample), was added during cooling. This "seeding" procedure has been shown to favour the formation of more uniform sized inulin crystals in a preliminary study. Finally the lemon flavour, preservatives and the water evaporated during the process were added, and then samples were transferred to closed flasks and stored in refrigeration $\left(4 \pm 1{ }^{\circ} \mathrm{C}\right)$ for $96 \mathrm{~h}$ before being evaluated.

\subsection{Rheological measurements}

All rheological measurements were carried out in a controlled stress rheometer (RheoStress 1, Karslruhe, Germany), monitored by a Rheowin Projob Manager, using a parallel-plates sensor system $(6 \mathrm{~cm}$ diameter and $1 \mathrm{~mm}$ gap). During measurements, temperature was kept constant at $10 \pm 1{ }^{\circ} \mathrm{C}$ using a Phoenix P1 Circulator device (Thermo Haake). At least two batches of each composition were prepared and one measurement was performed on each batch.

Flow behaviour was measured by recording shear stress values $(\sigma)$ when shearing the samples at linearly increasing shear rates $(\dot{\gamma})$ from 1 to $200 \mathrm{~s}^{-1}$ through $60 \mathrm{~s}$ and down in reverse sequence for the same duration. Areas under the upstream $\left(A_{\mathrm{up}}\right)$ and under the downstream $\left(A_{\text {down }}\right)$ as well as the thixotropic area $\left(A_{\text {up }}-A_{\text {down }}\right)$ were obtained.

Upstream data were fitted to the Ostwald-de Waele model $\left(\sigma=K \dot{\gamma}^{\mathrm{n}}\right)$ using Rheowin Pro data software (version 2.93, Haake). In the model $\mathrm{K}$ corresponds to the consistency index in Pa $\mathrm{s}$ and $\mathrm{n}$ corresponds to the flow index (dimensionless).

Viscoelastic properties were measured using small amplitude oscillatory shear tests. First, to determine the linear viscoelastic region, stress sweeps were run at $1 \mathrm{~Hz}$. After that, the frequency sweeps were performed over the range $\mathrm{f}=0.1-10 \mathrm{~Hz}$ and the values of the storage modulus $\left(G^{\prime}\right)$, the loss modulus $\left(G^{\prime \prime}\right)$, the loss tangent angle $(\tan \delta)$ and the complex viscosity $\left(\eta^{*}\right)$, as a function of frequency, were calculated using the Rheowin Pro software (version 2.93, Haake).

\subsection{Sensory evaluation}

Sensory evaluation was carried out in a standardized test room (ISO, 2007 ) in morning sessions. Samples ( $40 \mathrm{ml}$ ) were served at $10 \pm 1^{\circ} \mathrm{C}$ in white plastic cups coded with random three-digit numbers. Samples evaluated in each session were served in an order following a Williams design (MacFie, Bratchell, Greenhoff, \& Vallis, 1989).

A total of 100 consumers were recruited by a local consumer association (AVACU) through a short questionnaire sent by mail. They were selected according to the following criteria: age (18 to 65), gender (woman and man) and consumers of semisolid dairy products like custard and/or yoghurt (at least one time at week). Demographic characteristics and consumption habits of participants are shown in Tables 2 and 3, respectively.

Each consumer evaluated the nineteen samples over four sessions ( 4 or 5 samples per session). They were asked to rate the adequacy of sample thickness on a 5-point just about right (JAR) scale ( 1 = too weak, $3=$ just about right; $5=$ too strong). Between samples mineral water and bread were provided to consumers to rinse their mouths. Data were collected using the Compusense ${ }^{\circledR}$ five 5.0 software (Compusense Inc., Guelph, Ontario, Canada). 
Table 2

Demographic and sociological characteristics of consumers $(n=100)$.

\begin{tabular}{lll}
\hline Characteristic & Category & Consumers (\%) \\
\hline Gender & Female & 65 \\
\multirow{2}{*}{ Age (years) } & Male & 35 \\
& $18-30$ & 52 \\
\multirow{3}{*}{ Marital status } & $31-45$ & 29 \\
& $>46$ & 19 \\
\multirow{3}{*}{ Ocupattion } & Single & 57 \\
& Married & 38 \\
& Other & 5 \\
& Employee & 52 \\
& Student & 37 \\
\hline
\end{tabular}

\subsection{Data analysis}

Variability in rheological parameters was studied by one way analysis of variance (ANOVA) and the significance of differences between samples was determined using the Fisher test $(\alpha \leq 0.05)$. XLSTAT-Pro Version 2007 (Addinsoft, Paris, France) was used.

In order to relate the studied variables with concentration, data were subjected to a multivariate regression analysis and fitted to a second-order model equation provided in the design given by RSM (Gacula, 1993):

$$
\begin{aligned}
\mathrm{Y}= & \mathrm{B}_{0}+\mathrm{B}_{1} \mathrm{X}_{1}+\mathrm{B}_{2} \mathrm{X}_{2}+\mathrm{B}_{3} \mathrm{X}_{3}+\mathrm{B}_{11} \mathrm{X}_{1}^{2}+\mathrm{B}_{22} \mathrm{X}_{2}^{2}+\mathrm{B}_{33} \mathrm{X}_{3}^{2}+\mathrm{B}_{12} \mathrm{X}_{12} \\
& +\mathrm{B}_{13} \mathrm{X}_{13}+\mathrm{B}_{23} \mathrm{X}_{23}+\text { Error }
\end{aligned}
$$

where $Y$ is the studied variable, $B_{0}$ is the intercept (constant), $B_{1}, B_{2}, B_{3}$ the linear, $\mathrm{B}_{11}, \mathrm{~B}_{22}, \mathrm{~B}_{33}$ the quadratic and $\mathrm{B}_{12}, \mathrm{~B}_{13}, \mathrm{~B}_{23}$ the interaction effects, $X_{1}, X_{2}$ and $X_{3}$ the independent variables: concentrations of sucrose, lemon flavor and inulin respectively. In the selected models, only the statistically significant parameters at $\mathrm{p} \leq 0.05$ were included based on the Student's test. Statgraphics Plus v. 4.1 (Statistical Graphics Corp. Warrenton, VA, USA).

To analyse data obtained with the JAR scale, first the percentage of consumers rating the thickness of sample in each point of scale was calculated. Secondly, the approach proposed by Gacula et al. (2007) was followed, estimating below and above deviations from point 3 on the scale (JAR). Individual scale scores $(1,2,3,4$ or 5$)$ were transformed to $(-2,-1,0,1$ or 2 , respectively). Two groups of data emerge from this calculation, one for those consumers who feel that the sample lacks the attribute (below the JAR) and another for those consumers who feel the product exceeds the attribute (above the JAR). For each sample, the mean of values below JAR point 3 corresponded to the negative deviation value (too little of the attribute) and the mean of values above JAR point 3 correspond to the positive deviation value (too much of the attribute).

Table 3

Frequency of consumption of different dairy products by participants.

\begin{tabular}{llll}
\hline & \multicolumn{2}{l}{$\begin{array}{l}\text { \% population that consumed the product } \\
\text { during }\end{array}$} \\
\cline { 2 - 4 } & Last month & Last week & Never \\
\hline Yogurt with regular fat content & 32 & 33 & 35 \\
Yogurt 0\% fat & 21 & 54 & 25 \\
Yogurt 0\% sugar & 23 & 31 & 46 \\
Yogurt with fruit & 20 & 54 & 26 \\
Yogurt with fibre & 26 & 24 & 50 \\
Yogurt with probiotic & 28 & 35 & 37 \\
Ice cream with regular fat content & 32 & 31 & 37 \\
Custard or similar dessert & 28 & 53 & 19
\end{tabular}

\section{Results and discussion}

\subsection{Rheological properties. Effect of composition}

All samples displayed time-dependent and pseudoplastic flow behavior, as can be seen in Fig. 1, where some of the flow curves are shown as an example. This is the typical behavior observed in semisolid starch-based products (Doublier \& Durand, 2008; Tárrega \& Costell, 2007) and it corresponds to the deformation resistance of the biphasic structure, given by the characteristics of the dispersed phase (starch granules) and the continuous phase (Nguyen, Jensen \& Kristensen, 1998; Thebaudin, Lefebvre, \& Doublier, 1998). Fig. 1 also shows that there are quantitative differences among desserts with different inulin, sucrose and lemon flavor concentrations. This is in accordance with previous studies in dairy desserts, showing that the compounds included in the continuous phase, such as some components of milk (Matser \& Steeneken, 1997), sucrose (Acquarone \& Rao, 2003; Sikora, Mazurkiewicz, Tomasik, \& Pielichowski, 1999) or different hydrocolloids (Kruger, et al, 2003; Liu, Eskin, \& Cui, 2003; Tecante \& Doublier, 1999) can modify the structure of the system and thus its rheological behaviour.

Flow time dependence was evaluated by calculating the thixotropic area and the upward flow curve data were fitted to the Ostwald-de Waele model $\left(0.976 \leq R^{2} \leq 0.998\right)$. To compare samples, the values of the thixotropic area, consistency index, flow index and apparent viscosity values at $10 \mathrm{~s}^{-1}$ were used (Table 4).

Analysis of variance indicated that the thixotropy, consistency and viscosity of samples varied significantly depending on the composition while pseudoplasticity did not vary significantly (Table 5). For each flow parameter, its relationship with composition was determined by fitting data to a second-order equation. According to the resulting models (Table 6 ), the differences in flow parameters can be explained by both concentration of sucrose and inulin. The thixotropic area increased linearly with sucrose and inulin concentrations (Fig. 2 a), whereas the consistency index and apparent viscosity at $10 \mathrm{~s}^{-1}$ increased in a quadratic way with both ingredients. For the consistency index these effects can be observed in Fig. 2b and a similar trend was observed for apparent viscosity at $10 \mathrm{~s}^{-1}$.

To study viscoelastic properties, mechanical spectra were obtained for each of the studied samples. All of them showed the typical behavior of weak gels with $G^{\prime}$ values above those of $G^{\prime \prime}$, both of which were quite frequency-dependent (Fig. 3.). The values of $\mathrm{G}^{\prime}$ and $\tan \delta$ were taken at $1 \mathrm{~Hz}$ (Table 4) and for both parameters ANOVA indicated significant differences among samples (Table 5). According to the model given by the multiple regression analysis (Table 6), $\mathrm{G}^{\prime}$

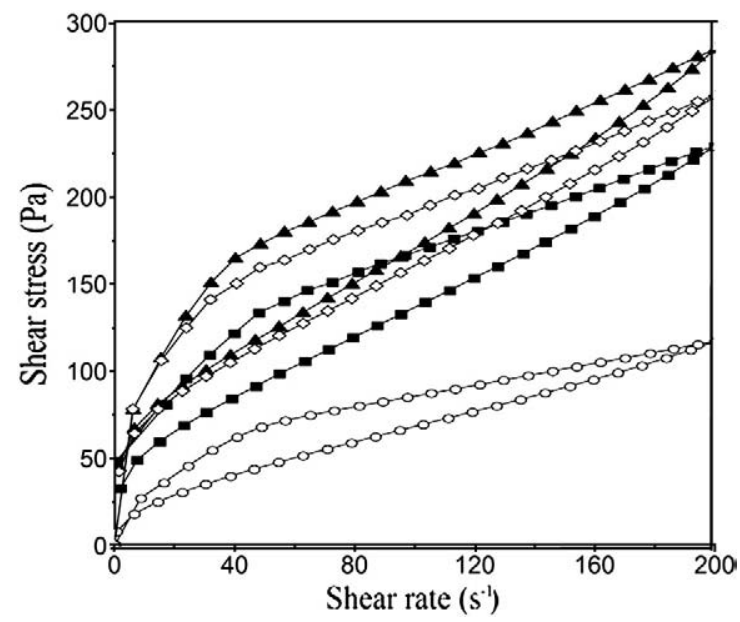

Fig. 1. Flow curves of samples: $1(O), 9(\boldsymbol{\square}), 11(\boldsymbol{\Delta})$ and $15(\diamond)$. Identification of samples in Table 1. 
Table 4

Mean values $(n=2)$ for the rheological parameters of dairy desserts ${ }^{\mathrm{a}}$. Identification of samples in Table 1.

\begin{tabular}{lllllll}
\hline Sample & $\begin{array}{l}\text { Thixotropic area } \\
\left(\text { Pa s }^{-1}\right)\end{array}$ & $\mathrm{k}\left(\right.$ Pa s$\left.^{\mathrm{n}}\right)$ & $\mathrm{n}$ & $\eta_{10}($ Pa s $)$ & $\mathrm{G}^{\prime}(\mathrm{Pa})$ & $\tan \delta$ \\
\hline 1 & $3513^{\mathrm{de}}$ & $14.0^{\mathrm{d}}$ & 0.41 & $3.60^{\mathrm{d}}$ & $27.9^{\mathrm{d}}$ & $0.69^{\mathrm{abc}}$ \\
2 & $5623^{\mathrm{abcde}}$ & $27.8^{\mathrm{c}}$ & 0.39 & $6.75^{\mathrm{bc}}$ & $73.2^{\mathrm{c}}$ & $0.60^{\mathrm{abcd}}$ \\
3 & $3327^{\mathrm{e}}$ & $16.0^{\mathrm{d}}$ & 0.40 & $4.00^{\mathrm{d}}$ & $30.5^{\mathrm{d}}$ & $0.71^{\mathrm{ab}}$ \\
4 & $5458^{\mathrm{bcde}}$ & $27.1^{\mathrm{c}}$ & 0.39 & $6.54^{\mathrm{bc}}$ & $82.2^{\mathrm{c}}$ & $0.48^{\text {defg }}$ \\
5 & $5067^{\mathrm{cde}}$ & $31.5^{\mathrm{bc}}$ & 0.36 & $7.17^{\mathrm{bc}}$ & $100.2^{\mathrm{c}}$ & $0.43^{\text {efgh }}$ \\
6 & $8131^{\mathrm{a}}$ & $40.9^{\mathrm{a}}$ & 0.41 & $10.54^{\mathrm{a}}$ & $200.7^{\mathrm{a}}$ & $0.34^{\text {gh }}$ \\
7 & $7697^{\mathrm{ab}}$ & $36.1^{\mathrm{ab}}$ & 0.34 & $7.93^{\mathrm{b}}$ & $111.4^{\mathrm{c}}$ & $0.43^{\text {efgh }}$ \\
8 & $6190^{\mathrm{abc}}$ & $42.5^{\mathrm{a}}$ & 0.39 & $10.24^{\mathrm{a}}$ & $198.0^{\mathrm{ab}}$ & $0.31^{\mathrm{h}}$ \\
9 & $5869^{\mathrm{abcd}}$ & $27.5^{\mathrm{c}}$ & 0.39 & $6.78^{\mathrm{bc}}$ & $104.2^{\mathrm{c}}$ & $0.46^{\text {defgh }}$ \\
10 & $3166^{\mathrm{e}}$ & $14.5^{\mathrm{d}}$ & 0.39 & $3.53^{\mathrm{d}}$ & $23.0^{\mathrm{d}}$ & $0.57^{\mathrm{bcde}}$ \\
11 & $6935^{\mathrm{abc}}$ & $44.0^{\mathrm{a}}$ & 0.39 & $10.29^{\mathrm{a}}$ & $158.3^{\mathrm{b}}$ & $0.34^{\text {gh }}$ \\
12 & $6749^{\mathrm{abc}}$ & $30.4^{\mathrm{bc}}$ & 0.37 & $7.12^{\mathrm{bc}}$ & $86.5^{\mathrm{c}}$ & $0.50^{\text {def }}$ \\
13 & $5612^{\mathrm{bcde}}$ & $25.5^{\mathrm{c}}$ & 0.38 & $6.16^{\mathrm{c}}$ & $92.0^{\mathrm{c}}$ & $0.47^{\text {defg }}$ \\
14 & $3174^{\mathrm{e}}$ & $12.7^{\mathrm{d}}$ & 0.44 & $3.51^{\mathrm{d}}$ & $25.2^{\mathrm{d}}$ & $0.74^{\mathrm{a}}$ \\
15 & $6107^{\mathrm{abc}}$ & $43.2^{\mathrm{a}}$ & 0.36 & $9.81^{\mathrm{a}}$ & $178.5^{\mathrm{ab}}$ & $0.37^{\text {fgh }}$ \\
16 & $4699^{\mathrm{cde}}$ & $25.3^{\mathrm{c}}$ & 0.39 & $6.19^{\mathrm{c}}$ & $80.1^{\mathrm{c}}$ & $0.50^{\text {defg }}$ \\
17 & $4825^{\mathrm{cde}}$ & $25.0^{\mathrm{c}}$ & 0.40 & $6.27^{\mathrm{c}}$ & $81.8^{\mathrm{c}}$ & $0.52^{\text {def }}$ \\
18 & $6457^{\mathrm{abc}}$ & $28.2^{\mathrm{bc}}$ & 0.37 & $6.58^{\mathrm{bc}}$ & $79.2^{\mathrm{c}}$ & $0.53^{\text {cde }}$ \\
19 & $4449^{\text {cde }}$ & $24.2^{\mathrm{c}}$ & 0.38 & $5.80^{\mathrm{c}}$ & $92.4^{\mathrm{c}}$ & $0.49^{\text {defg }}$ \\
\hline
\end{tabular}

${ }^{a}$ For each parameter, values not shearing letters differ significantly $(p=0.05)$.

values mainly depended on inulin concentration but also on its interaction with sucrose concentration. Thus, sample elasticity increased in line with inulin concentration in a quadratic way and the higher the sucrose concentration in the sample, the greater the increase. For $\tan \delta$, values decreased linearly with the sucrose and inulin concentrations. A contour plot of viscoelastic properties is given in Fig. 4.

According to rheological results, the addition of mixed short and long-chain inulin was able to modify the rheological properties of dairy dessert. The effect depended not only on the inulin concentration but also on the sucrose concentration, thus giving a wide range of products with different rheological behaviour. While differences in consistency were attributed to sucrose concentration and inulin concentration, the differences in elasticity were mainly due to inulin concentration and its interaction with sucrose. This can be explained by the different way in which the two ingredients modify the continuous phase of the system. Sucrose became a solute in the continuous phase, binding water molecules, thus increasing the viscosity of the continuous phase of the system. In the case of inulin, the short-chain molecules would also remain solubilised in the continuous phase and cause the same effect as sucrose. However, long-chain inulin has the ability to crystallize and

Table 5

Analysis of variance of one factor (sample) of rheological parameters. F and p values. Degree of freedom $=18$.

\begin{tabular}{lllllllll}
\hline & Flow & & & & \multicolumn{2}{c}{ Viscoelasticity } \\
\cline { 2 - 3 } & Thixotropic area & $\mathrm{k}$ & $\mathrm{n}$ & $\eta_{10}$ & & $\mathrm{G}^{\prime}$ & $\tan \delta$ \\
\hline $\mathrm{F}$ & 3.0 & 12.9 & 1.3 & 18.4 & & 15.9 & 5.4 \\
$p$ & 0.011 & $<0.001$ & 0.267 & $<0.001$ & & $<0.001$ & $<0.001$ \\
\hline
\end{tabular}

Table 6

Regression models relating rheological parameters with inulin (I), sucrose (S) and lemon flavor (L) concentrations.

\begin{tabular}{ll}
\hline Model & $\mathrm{R}^{2}$ \\
\hline Thixotropic area $=233.62 \mathrm{~S}+520.19 \mathrm{I}$ & 0.95 \\
$\mathrm{k}=0.624+0.103 \mathrm{~S}^{2}+0.435 \mathrm{I}^{2}$ & 0.87 \\
$\eta$ at $10 \mathrm{~s}^{-1}=0.429+0.026 \mathrm{~S}^{2}+0.095 \mathrm{I}^{2}$ & 0.90 \\
$\mathrm{G}^{\prime}$ at $1 \mathrm{~Hz}=-50.30+0.89 \mathrm{I}^{2}+1.88 \mathrm{SI}$ & 0.90 \\
$\tan \delta$ at $1 \mathrm{~Hz}=1.125-0.020 \mathrm{~S}-0.071 \mathrm{I}$ & 0.76
\end{tabular}

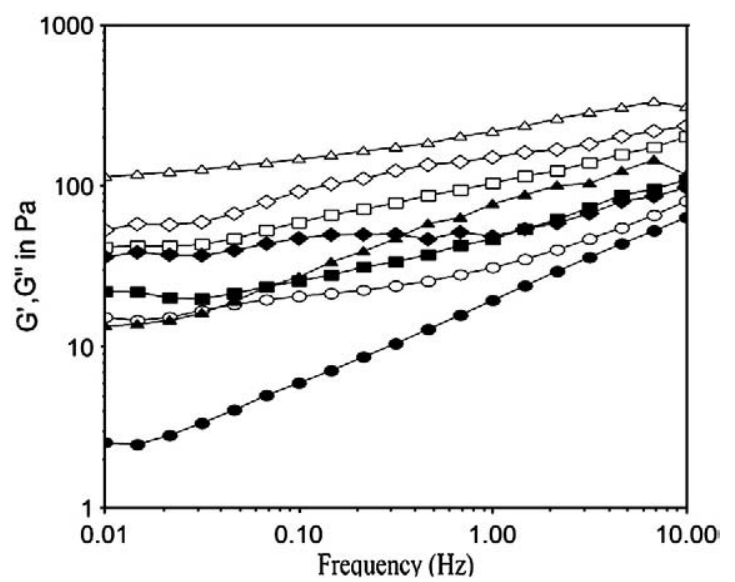

Fig. 2. Contour plot of the model relating: a) thixotropic area in $\mathrm{Pa} \mathrm{s}^{-1}$, and b) consistency index in $\mathrm{Pa}^{\mathrm{n}}$ with inulin concentration and sucrose concentration.

form aggregates (Torres, Tárrega, \& Costell, 2010); therefore, by this mechanism, apart from occluding water, it creates a new structure within the continuous phase which is responsible for increasing the elastic response of the system. As indicated by the interaction effect, sucrose contributed to elasticity indirectly. The effect of inulin on
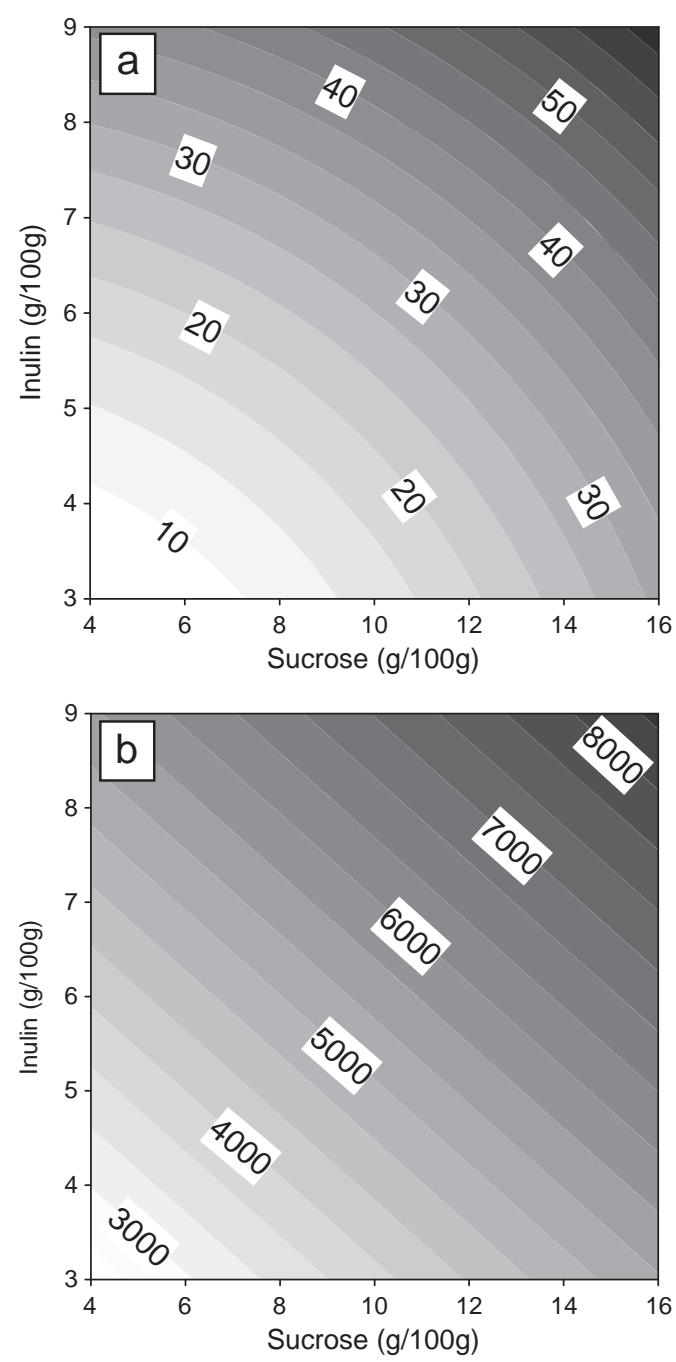

Fig. 3. Mechanical spectra of samples: $1(\bullet), 9(\boldsymbol{\square}), 11(\boldsymbol{\Delta})$ and $15(\bullet)$. Values of $\mathrm{G}^{\prime}$ (filled symbols) and G" (open symbols). Identification of samples in Table 1. 

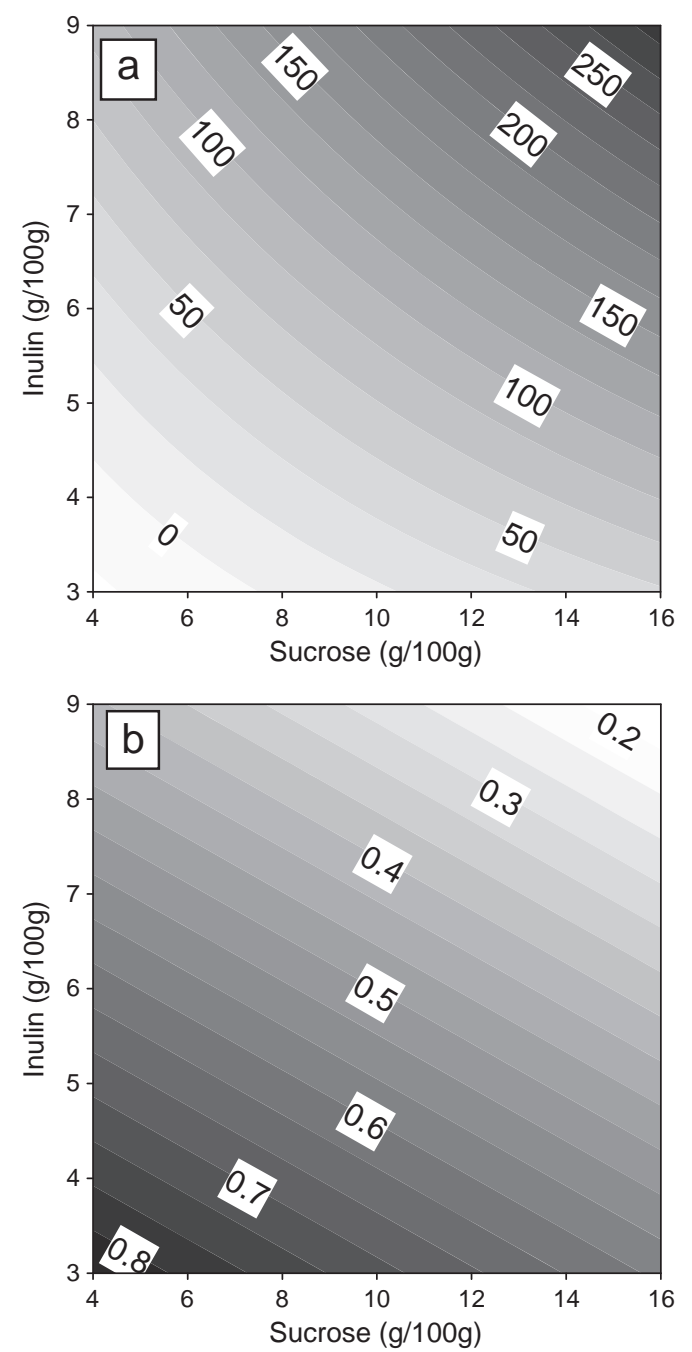

Fig. 4. Contour plot of the model relating: a) elastic modulus in Pa, and b) $\tan \delta$ with inulin concentration and sucrose concentration.

elasticity was higher for high sucrose samples due to the water retention ability of sucrose, which increased the inulin effective concentration. Finally, with regard to lemon flavour, although changes in rheological properties due to food flavour components have been reported in some cases (Lubbers \& Decourcelle, 2004), in our study the concentration of lemon flavor did not affect any of the rheological parameters studied.

\subsection{Thickness suitability assessed by consumers. Effect of composition}

The JAR scale was used to evaluate thickness appropriateness of a lowfat dessert to determine how much each sample varied or approached the desirable level for this product. The percentage of consumers that considered thickness to be just about right varied greatly among samples, from $19 \%$ for sample 6 to $70 \%$ for sample 9 (central point of the design) (Table 7). The model explaining the relationship between the percentage of consumers considering thickness as JAR (\% Consumer in JAR 3) and sample composition (S: Sucrose; I: Inulin) is as follows:

$$
\begin{aligned}
\text { \%Consumers in JAR3 }= & -407.60+82.66 \mathrm{I}+47.99 \mathrm{~S}-3.83 \mathrm{I}^{2} \\
& -1.26 \mathrm{~S}^{2}-3.94 \mathrm{II} \\
R^{2}= & 0.94
\end{aligned}
$$

Both sucrose and inulin concentration significantly affected thickness appropriateness, showing an inverted $U$-shape relationship within the concentration ranges considered in this study (Fig. 5a). The most
Table 7

Percentage of consumers considering thickness as JAR and positive and negative deviation values for each dairy dessert sample. Identification of samples in Table 1.

\begin{tabular}{llll}
\hline Sample & $\begin{array}{l}\text { Consumers } \\
\text { considering } \\
\text { thickness as } \\
\text { JAR (\%) }\end{array}$ & Deviation & \\
\cline { 3 - 4 } & 38 & Too little & Too much \\
\hline 1 & 65 & -0.72 & \\
2 & 30 & -0.11 & 0.03 \\
3 & 65 & -0.83 & 0.26 \\
4 & 59 & -0.25 & 0.01 \\
5 & 19 & -0.04 & 0.12 \\
6 & 65 & 0.00 & 0.45 \\
7 & 25 & -0.06 & 1.22 \\
8 & 69 & 0.00 & 0.40 \\
9 & 30 & -0.15 & 1.08 \\
10 & 20 & -0.88 & 0.20 \\
11 & 69 & -0.02 & 0.03 \\
12 & 69 & -0.19 & 1.15 \\
13 & 45 & -0.18 & 0.13 \\
14 & 27 & -0.60 & 0.16 \\
15 & 65 & -0.01 & 0.04 \\
$16^{\mathrm{a}}$ & 65 & -0.13 & 0.93 \\
$17^{\mathrm{a}}$ & 78 & -0.09 & 0.22 \\
$18^{\mathrm{a}}$ & 72 & -0.02 & 0.28 \\
$19^{\mathrm{a}}$ & 65 & -0.24 & 0.21 \\
\hline
\end{tabular}

a Samples 16 to 19 are replication of the central point (sample 9).
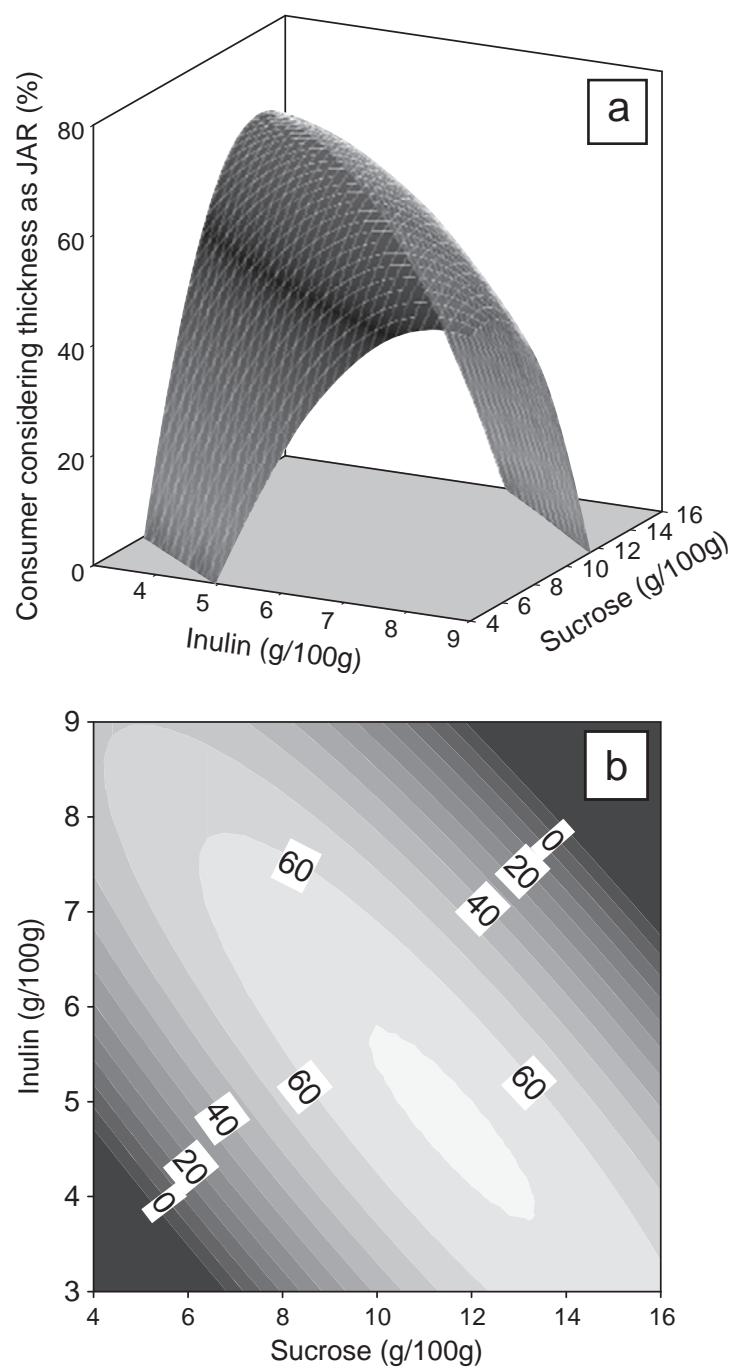

Fig. 5. Relation between percentage of consumers considering thickness of samples as JAR and sucrose concentration and inulin concentration. Response surface (a) and contour plot (b). 
adequate thickness corresponded to samples with intermediate levels of inulin and sucrose. Due to the interaction effect, the combination of low sucrose-high inulin and vice-versa also led to samples with adequate thickness (Fig. 5b).

For consumers who did not consider thickness as adequate but considered it as "too much" or "too little", thickness deviation from the JAR was calculated for each sample (Table 7). Deviation values depended on both inulin and sucrose content. The effect of inulin depended on sucrose concentration and vice-versa. On one hand the addition of inulin at low concentrations $(\leq 4.5 \%)$ resulted in samples with too weak thickness but only when sucrose content was $\leq 10 \%$ (samples 1, 3, and 14). On the other hand, inulin addition at high concentration $(\geq 7.5 \%)$ resulted in samples whose thickness was considered excessive. The effect was slight for samples with low sucrose level (5 and 7) and strong for high sucrose levels (6, 8 and 15).

Regarding the effect of sucrose, samples with low levels $(\leq 7 \%)$ were not thick enough if inulin concentration was $\leq 6 \%$ (samples 1,3 and 10) and too much thick samples were obtained with high sucrose levels ( $\geq 13 \%$ ) if inulin concentration was $\geq 6 \%$ (samples 6,8 and 11 ).

\subsection{Relationship between rheological properties and thickness suitability}

Both rheological parameters and thickness adequacy assessed by consumers have been shown to vary with desserts composition. From a practical viewpoint, it could be interesting to know how the desirable thickness level can be associated with the values of certain rheological parameters. To do so, two different graphical approaches were used. The first one based on the percentage of consumers that considered thickness as JAR and the second one based on the JAR deviations. All rheological parameters were studied and only those showing a relation with the thickness intensity assessed by consumers are discussed below.

Given the flow parameters, both consistency index and apparent viscosity at $10 s^{-1}$ showed to be related with thickness adequacy. The relationship between the consistency index and the consumer percentage that considered thickness as JAR is shown in Fig. 6a and a similar plot was obtained for apparent viscosity at $10 \mathrm{~s}^{-1}$. According to them, samples with $\mathrm{K}$ values in the range of $25-37 \mathrm{~Pa} \mathrm{~s}^{\mathrm{n}}$ or with $\eta_{10}$ values in the range of 5.8-7.9 Pa s were those with the most desirable thickness (considered by over $60 \%$ consumers as JAR). Thickness of samples with $\mathrm{K}$ values below $16 \mathrm{~Pa} \mathrm{~s}^{\mathrm{n}}$ and above $40 \mathrm{~Pa} \mathrm{~s}^{\mathrm{n}}$ ( $\eta_{10}$ values below 4.0 Pa s and above 9.8 Pa s) was considered inadequate by over $55 \%$ and $70 \%$ of consumers, respectively. In the second approach the relationship between the consistency index and the "too little" and "too much" deviation of JAR thickness was studied (Fig. 6.b). In this study, a relevant deviation was considered to exist only when the value was above 0.25 and below -0.25 for "too much" and "too little", respectively (dotted line). According to this criterion, samples with $K$ values between 25 and 31 Pa s $s^{n}$ or $\eta_{10}$ between 5.8 and 7.1 with did not deviate from ideal thickness. As can be observed, the obtained range of $\mathrm{k}$ and $\eta_{10}$ values could differ depending on the approach. Values of $\mathrm{K}$ from 31 to $37 \mathrm{~Pa} \mathrm{~s}^{\mathrm{n}}$ and values of $\eta_{10}$ from 7.1 to 7.9 Pa s, which according to the first approach corresponded to adequate thickness, were not included in the second approach because for these cases, although over $60 \%$ of consumers considered thickness as JAR, the rest of consumers coincided in considering the samples as too thick. A similar procedure was followed to assess viscoelastic parameters, with the storage modulus proving to be the most closely related with thickness adequacy. According to Fig. 7a, samples with $\mathrm{G}^{\prime}$ values in the range of 73$112 \mathrm{~Pa}$ were those with the most desirable thickness. Thickness of samples with $\mathrm{G}^{\prime}$ values below $31 \mathrm{~Pa}$ and above 150 Pa were considered inadequate. The relationship between $\mathrm{G}^{\prime}$ and both "too little" and "too much" deviation of JAR thickness is shown in Fig. 7b. As observed in the consistency index, the ranges of $\mathrm{G}^{\prime}$ values were narrower for this second approach. In this case, samples without relevant deviation from JAR thickness were those with $\mathrm{G}^{\prime}$ values between 73 and $100 \mathrm{~Pa}$.
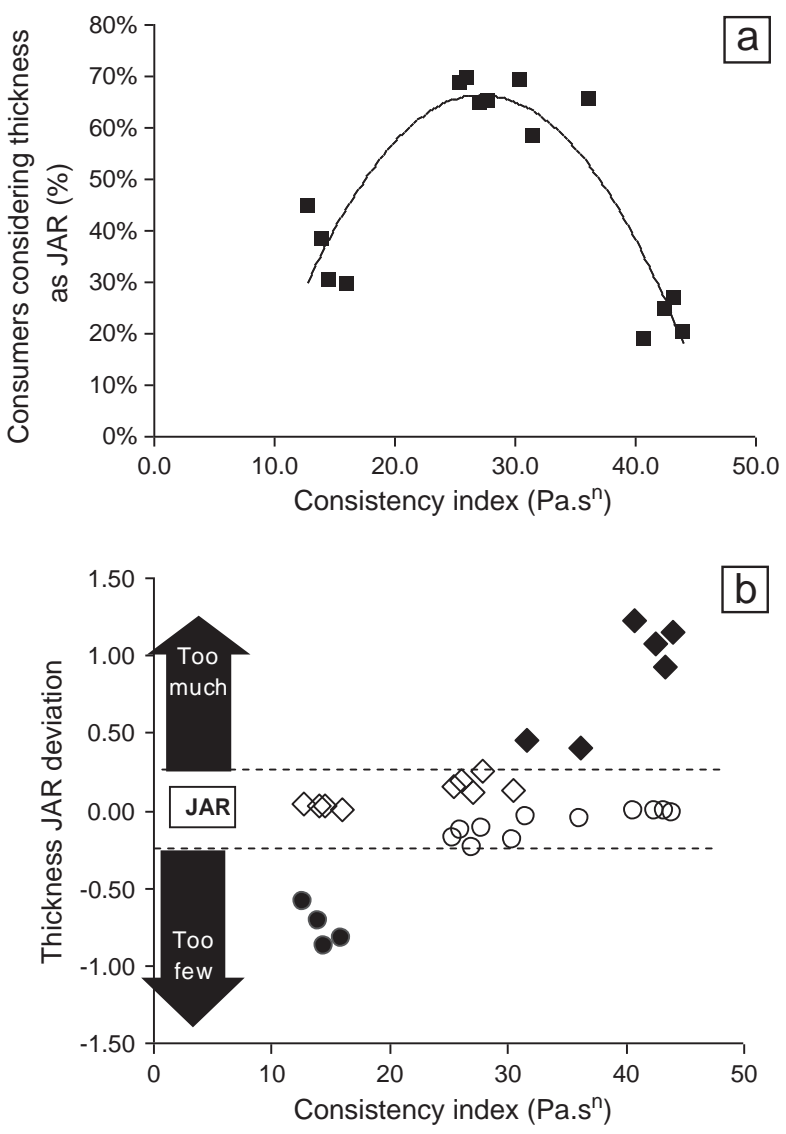

Fig. 6. Consistency index related to the percentage of consumers considering thickness as JAR (a) and to JAR thickness deviation (b). Values of too much deviation (diamond) and too little deviation (circle) considered as relevant $(>0.25,-)$ have filled symbol.

Both flow and viscoelastic measurements provided instrumental indexes of the adequacy of semisolid desserts thickness. Flow curve parameters (consistency and viscosity) are obtained under large deformation values and elastic modulus is obtained at small deformation ones. They reflect different phenomena and can give different and complementary information. In this work variation of consistency and viscosity values among samples did not follow exactly the same pattern than values of the elastic modulus (Table 4). However both types of parameters showed the same relation with thickness adequacy. This indicates that the slight differences among parameters are not implicated in how much adequate thickness was perceived by consumers. From a practical viewpoint, each of selected rheological parameters $\left(K, \eta_{10}\right.$, and $\mathrm{G}^{\prime}$ at $1 \mathrm{~Hz}$ ) can be used as instrumental index of thickness suitability in this type of products.

\section{Conclusions}

Flow and viscoelastic properties of dairy desserts enriched with a mixture of short and long-chain inulin vary greatly with composition. By varying both inulin and sucrose concentrations a wide range of products with different rheological properties can be obtained. These differences in the dairy desserts are also perceived by consumers as differences in thickness adequacy. An inulin-enriched dessert with the most ideal thickness can be achieved through formulations containing inulin in the range from 3.5 to $6 \%$ and adjusting the sucrose amount. For this type of product, the most desirable thickness level corresponds to consistency index values between 25-31 Pa s ${ }^{\mathrm{n}}$, apparent viscosity values at $10 \mathrm{~s}^{-1}$ between 5.8-7.1 Pa s and $\mathrm{G}^{\prime}$ values between 73-100 Pa. 

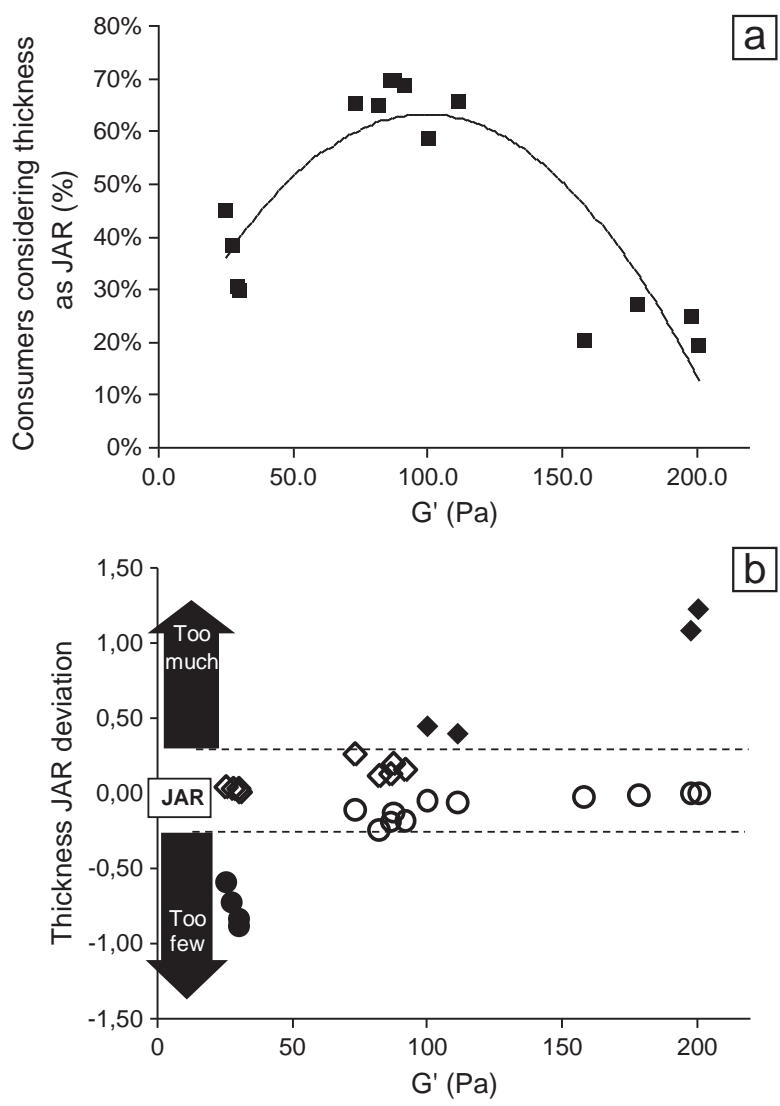

Fig. 7. Storage modulus related to the percentage of consumers considering thickness as JAR (a) and to JAR thickness deviation (b). Values of too much deviation (diamond) and too little deviation (circle) considered as relevant $(>0.25,-)$ have filled symbol.

JAR methodology is a useful tool to assess attribute adequacy. As shown in this work, data thus obtained can be related with instrumental measurements to determine which parameters and ranges can be taken as indicators of the desirable level for each attribute. From a practical point of view, this information could be useful in product reformulation to preliminarily evaluate sample adequacy by means of instrumental measurements, instead of the more time-consuming and expensive consumer tests.

\section{Acknowledgments}

To MICINN of Spain for financial support (AGL 2007-63444). To Fondo Social Europeo for financing author Tarrega (JAE programme, CSIC). To Laboratorio Tecnológico del Uruguay for financing the stage training of author Arcia. To CHR Hansen S.A., Lucta S.A., Brenntag Quimica and Central Lechera Asturiana for providing free samples of the ingredients.

\section{References}

Acquarone, V. M., \& Rao, M. A. (2003). Influence of sucrose on the rheology and granule size of cross-linked waxy maize starch dispersions heated at two temperatures. Carbohydrate Polymers, 51, 451-458.

Bayarri, S., Chuliá, I., \& Costell, E. (2010). Comparing lambda-carrageenan and an inulin blend as fat replacers in carboxymethyl cellulose dairy desserts. Rheological and sensory aspects. Food Hydrocolloids, 24, 578-587.

Biedrzycka, E., \& Bielecka, M. (2004). Prebiotic effectiveness of fructans of different degrees of polymerization. Trends in Food Science and Technology, 15, 170-175.

Bult, J. H. F., De Wijk, R. A., \& Hummel, T. (2007). Investigations on multimodal sensory integration: texture, taste, ortho- and retronasal stimuli in concert. Neuroscience Letters, 411, 6-10.
Cayot, N., Lafarge, C., Arvisenet, G., \& Taisant, C. (2000). Influence of aroma compounds on the mechanical properties of starch-based food systems. Journal of Texture Studies, 31, 297-313.

Chiavaro, E., Vittadini, E., \& Corradini, C. (2007). Physicochemical characterization and stability of inulin gels. European Food Research and Technology, 225, 85-94.

Costell, E., Tárrega, A., \& Bayarri, S. (2010). Food acceptance: the role of consumer perception and attitudes. Chemosensory Perception, 3, 42-52.

Coudray, C., Tressol, J. C., Gueux, E., \& Rayssiguier, Y. (2003). Effects of inulin-type fructans of different chain length and type of branching on intestinal absorption and balance of calcium and magnesium in rats. European Journal of Nutrition, 42, 91-98.

de Wijk, R. A., van Gemert, L. J., Terpstra, M. E. J., \& Wilkinson, C. L. (2003). Texture of semi-solids; sensory and instrumental measurements on vanilla custard desserts. Food Quality and Preference, 14(4), 305-317.

Dickinson, E. (2007). Food colloids... How do interactions of ingredients control structure, stability and rheology? Current Opinion in Colloid and Interface Science, 12, $155-157$.

Doublier, J. L., \& Durand, S. (2008). A rheological characterization of semi-solid dairy systems. Food Chemistry, 108, 1169-1175.

Gacula, M. (1993). Design and Analysis of Sensory Optimization. Trumbull: Food and Nutrition Press.

Gacula, M., Rutenbeck, S., Pollack, L., Resurreccion, A., \& Moskowitz, H. (2007). The justabout-right intensity scale: functional analyses and relation to hedonic. Journal of Sensory Studies, 22, 194-211.

González-Tomás, L., Bayarri, S., Coll-Marqués, J., \& Costell, E. (2009). Flow behaviour of inulin-enriched dairy desserts: influence of inulin average chain length. International Journal of Food Science E Technology, 44, 1214-1222.

González-Tomás, L., \& Costell, E. (2006). Sensory evaluation of vanilla-dairy desserts by repertory grid method and free choice profile. Journal of Sensory Studies, 21(1), 20-33.

Hasler, C. M. (1998). Functional foods: their role in disease prevention and health promotion. Food Technology, 52(11), 63-70.

Hébette, C. L. M., Delcour, J. A., Koch, M. H. J., Booten, K., Kleppinger, R., \& Mischenkod, N. (1998). Complex melting of semi-crystalline chicory (Cichorium intybus L.) root inulin. Carbohydrate Research, 310, 65-75.

Hill, M. A., Mitchell, J. R., \& Sherman, P. A. (1995). The relationship between the rheological and sensory properties of a lemon pie filling. Journal of Texture Studies, $26,457-470$.

ISO (2007). General Guidance for the Design of Test Room. Standard No 8589:2007. Geneva, Switzerland: International Organization for Standardization.

Kohyama, K., \& Nishinari, K. (1991). Effect of soluble sugars on gelatinization and retrogradation of sweet potato starch. Journal of Agricultural and Food Chemistry, 39, $1406-1410$

Kruger, A. Ferrero, C. \& Zaritzky, N. E. (2003). Modelling corn starch swelling in batch systems: effect of sucrose and hydrocolloids. Journal of Food Engineering, 58, 125-133.

Liu, H., Eskin, N. A. M., \& Cui, S. W. (2003). Interactions of wheat and rice starches with yellow mustard mucilage. Food Hydrocolloids, 17, 863-869.

Lubbers, S., \& Decourcelle, N. (2004). Influence of Aroma Compounds on the Mechanical Properties of Pectin Gels. Journal of Agricultural and Food Chemistry, 52(5), 3077-3082.

MacFie, H. J., Bratchell, N., Greenhoff, K., \& Vallis, L. V. (1989). Designs to balance the effect of order of presentation and first-order carry over effects in Hall Tests. Journal of Sensory Studies, 4, 129-148.

Matser, A. M., \& Steeneken, P. A. M. (1997). Rheological properties of highly crosslinked waxy maize starch in aqueous suspensions of skim milk components. Effects of the concentration of starch and skim milk components. Carbohydrate Polymers, 32, 297-305.

Milner, J. A. (1999). Functional foods and health promotion. The Journal of Nutrition, 129 (7), 1395-1397.

Nguyen, Q. D., Jensen, C. T. B., \& Kristensen, P. G. (1998). Experimental and modelling studies of the flow properties of maize and waxy maize starch pastes. Chemical Engineering Journal, 70, 165-171.

Paseephol, T., Small, D. M., \& Sherkat, F. (2008). Rheology and texture of set yogurt as affected by inulin addition. Journal of Texture Studies, 39(6), 617-634.

Purwanti, N., van der Goot, A. J., Boom, R. \& Vereijken, J. (2010). New directions towards structure formation and stability of protein-rich foods from globular proteins. Trends in Food Science and Technology, 21, 85-94.

Richardson, R. K., Morris, E. R., Ross-Murphy, S. B., Taylor, L. J., \& Dea, I. C. M. (1989). Characterization of the perceived texture of thickened systems by dynamic viscosity measurements. Food Hydrocolloids, 3, 175-191.

Roberfroid, M. B. (2007). Inulin-type fructans: functional food ingredients. The Journal of Nutrition, 137, 2493-2502.

Sikora, M., Mazurkiewicz, J., Tomasik, P., \& Pielichowski, K. (1999). Rheological properties of some starch-water-sugar systems. International Journal of Food Science E' Technology, 34, 371-383.

Soukoulis, C., Lebesi, D., \& Tzia, C. (2009). Enrichment of ice cream with dietary fibre: effects on rheological properties, ice crystallisation and glass transition phenomena. Food Chemistry, 115(2), 665-671.

Tárrega, A., \& Costell, E. (2006). Effect of inulin addition on rheological and sensory properties of fat-free starch-based dairy desserts. International Dairy Journal, 16, 1104-1112.

Tárrega, A., \& Costell, E. (2007). Colour and consistency of semi-solid dairy desserts: instrumental and sensory measurements. Journal of Food Engineering, 78(2), $655-661$.

Tárrega, A., Rocafull, A., \& Costell, E. (2010). Effect of blends of short and long-chain inulin on the rheological and sensory properties of prebiotic low-fat custards. LWT Food Science and Technology, 43(3), 556-562. 
Tecante, A., \& Doublier, J. L. (1999). Steady flow and viscoelastic behavior of crosslinked waxy cornstarch-k-carrageenan pastes and gels. Carbohydrate Polymers, 40, $221-231$.

Thebaudin, J. Y., Lefebvre, A. C., \& Doublier, J. L. (1998). Rheology of starch pastes from starches of different origins: applications to starch-based sauces. Lebensmitttel Wissenschaft und Thecnologie, 31, 354-360.
Torres, J. D., Tárrega, A., \& Costell, E. (2010). Storage stability of starch-based dairy desserts containing long-chain inulin: rheology and particle size distribution. International Dairy Journal, 20(1), 46-52.

Van Vliet, T. (2002). On the relation between texture perception and fundamental mechanical parameters for liquids and time dependent solids. Food Quality and Preference, 13, 227-236. 